03;09

\title{
Эфффекты синхронизации и выключения автоколебаний химической реакции при периодическом воздействии света
}

\author{
(ㄱ Д.А. Усанов, А.П. Рытик , О.Ю. Кутикова
}

Саратовский национальный исследовательский государственный университет им. Н.Г. Чернышевского, Саратов, Россия

『E-mail: ra4csz@ya.ru

Поступило в Редакцию 1 марта 2018 г.

Исследован эффект синхронизации химических концентрационных автоколебаний реакции Бриггса-Раушера при внешнем периодическом воздействии белого света. Выявлено изменение частоты концентрационных колебаний вне полосы синхронизации при внешнем воздействии света с частотой модуляции от 0.029 до $0.039 \mathrm{~Hz}$ до начала синхронизации и от 0.1 до $0.14 \mathrm{~Hz}$ после нее. Показана зависимость полосы синхронизации от мощности, установлены предельные значения мощности внешнего светового воздействия, при которых автоколебания „выключаются“. Выявлен диапазон синхронизации концентрационных колебаний при внешнем световом воздействии с частотой модуляции из диапазона $0.04-0.1 \mathrm{~Hz}$. Установлено, что при световом потоке от источника освещения более $5000 \mathrm{~lm}$ автоколебательный процесс реакции выключается.

DOI: 10.21883/PJTF.2018.24.47027.17272

Реакция Бриггса-Раушера („иодные часы“) - автоколебательная химическая реакция, в ходе которой периодически изменяется цвет смеси пероксида водорода $\mathrm{H}_{2} \mathrm{O}_{2}$, серной, малоновой кислот и крахмала: с бесцветного на золотой (желтый), синий [1]. Колебательный процесс реакции основан на двойственной роли $\mathrm{H}_{2} \mathrm{O}_{2}$ как окислителя и восстановителя. Процесс запуска реакции подробно описан в [2], он состоит в приготовлении составляющих растворов и их смешении. Таким образом, полученная смесь составляет среду реакции. В этой среде происходит изменение числа молекул (концентрации) растворенного кислорода. Такого рода изменения называются концентрационными колебаниями. Автоколебательные химические реакции обладают высокой чувствительностью к воздействию внешних факторов [3]. Известны, в 


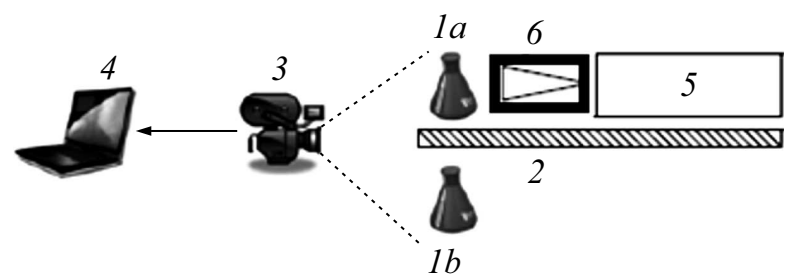

Рис. 1. Схема эксперимента. Пояснение в тексте.

частности, работы по влиянию света на автоколебательные реакции, одной из которых является реакция Бриггса-Раушера (БР). Авторы работы [4] исследовали эффект влияния непрерывного потока света на характер осцилляций среды реакции БР; реакция находилась в трех различных состояниях: возбужденном устойчивом, бистабильном и в состоянии квазигармонических релаксационных колебаний. Поставлены эксперименты с непрерывным освещением, с периодическим освещением различной частоты и длительности световых импульсов. В качестве чувствительной тест-системы был выбран автоколебательный режим химической реакции БР [5]. Отметим, что реакция БР принадлежит к многочисленному классу химических реакций, в которых наблюдаются автоколебательные процессы. Можно ожидать, что наблюдаемые в реакциях БР эффекты будут проявляться и в других типах автоколебательных химических реакций. В таких процессах могут наблюдаться явления, характерные для автоколебаний любой природы, в том числе широко изучаемые в радиофизике. В качестве одного из таких процессов можно назвать явление синхронизации колебаний внешнего сигнала. Цель настоящей работы состоит в выявлении изменения характера концентрационных колебаний реакции Бриггса-Раушера при различных параметрах периодического воздействия света.

Производилась видеорегистрация изменений в среде реакции в ходе эксперимента. Схема экспериментальной установки, используемой для регистрации изменений характеристик реакции, приведена на рис. 1.

Растворы в двух колбах $1 a$ (облученная) и $1 b$ (контрольная) были разделены оптически непрозрачным электромагнитным экраном 2 (рис. 1). С помощью видеокамеры Sony HDR 220E (3) производилась видеорегистрация протекания автоколебательной реакции в видимой

3 Письма в ЖТФ, 2018, том 44, вып. 24 
области оптического диапазона. Данные в режиме реального времени поступали через порт USB в компьютер 4, где с помощью программной обработки осуществлялись запись видеокадров, обработка и вывод результатов. Перед анализом серии видеокадров проводилась калибровка баланса белого цвета каждого кадра. Облучение выполнялось лампой накаливания 5 с импульсным модулятором 6.

Источником света служила лампа накаливания 5 со световым потоком около $250 \mathrm{~lm}$, которая устанавливалась над колбой с реакцией БР (объем реакционной среды составлял $12 \mathrm{ml}$, при этом высота столба жидкости была $2 \mathrm{~cm})$. Для контроля использовалась реакция, которая шла без освещения.

Анализ полученных данных осуществлялся с помощью программы MS Excel 2007. Были проведены эксперименты с периодическим воздействием света. Период $(T)$ был равен $35,30,25,20,15,10,7$ и $6 \mathrm{~s}$, что соответствовало частотам от 0.03 до $0.17 \mathrm{~Hz}$. При этом скважность импульсов света составляла $5 \mathrm{~s}$.

При воздействии периодического освещения $250-5000 \mathrm{~lm}$ и изменении частоты $f$ внешних периодических воздействий от 0.04 до $0.05 \mathrm{~Hz}$ увеличилось количество колебаний реакции (в сравнении с контрольной) приблизительно в 2 раза. Из проведенной серии экспериментов следовало, что в определенной полосе частот модуляции собственная частота колебаний БР совпадала с частотой внешнего светового воздействия и скорость протекания реакции „успевала“ за внешним воздействием света. Были определены границы диапазона такой синхронизации. Отметим, что при включении света (скорость нарастания светового потока менее одной секунды) потенциал на ионоселективном электроде начинал возрастать, а при выключении резко уменьшался. Подобное навязывание частоты колебаний реакции внешними колебаниями светового потока с заданным периодом становилось возможным только в окрестности частоты собственных колебаний реакции.

Анализ полученных данных показал, что если период воздействия несколько меньше или больше периода собственного автоколебательного режима $(T=35,30,8,7 \mathrm{~s})$, то наблюдалось изменение частоты колебаний вне полосы синхронизации. При частоте воздействия с периодом, близким к периоду собственных колебаний БР, например $25 \mathrm{~s}$ $(0.04 \mathrm{~Hz})$, при световом потоке из диапазона $250-3000 \mathrm{~lm}$ собственные колебания БР постепенно синхронизируются с вынужденными колебаниями. Для периода внешнего воздействия от 30 до $10 \mathrm{~s}$ (от 0.03

Письма в ЖТФ, 2018, том 44, вып. 24 


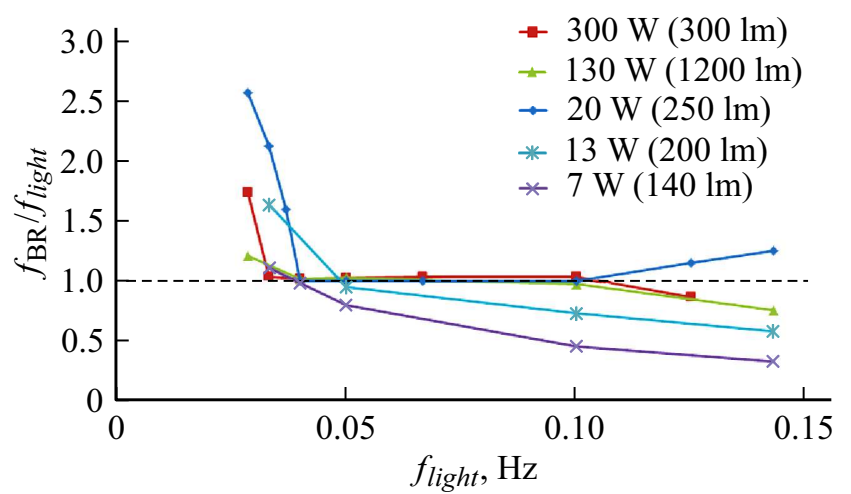

Рис. 2. Зависимость средней частоты осцилляций при различной частоте модуляции освещения для разных мощностей излучения. По оси абсцисс отложена частота модуляции внешнего освещения $f_{\text {light }}$, по оси ординат отношение частоты осцилляций среды реакции БР к частоте модуляции внешнего освещения $f_{\mathrm{BR}} / f_{\text {light }}$.

до $0.1 \mathrm{~Hz}$ ) при использовании лампы со световым потоком более $250 \mathrm{~lm}$ частота колебаний БР становилась равной частоте внешнего воздействия, т.е. наблюдался эффект синхронизации. Таким образом, было установлено, что диапазон синхронизации при внешнем световом воздействии составил $0.04-0.1 \mathrm{~Hz}$. Из данных, приведенных на рис. 2 , видно, что наблюдается изменение частоты в направлении частоты модуляции воздействующего светового потока в диапазоне $0.03-0.15 \mathrm{~Hz}$ при световом потоке от источника освещения более $200 \mathrm{~lm}$.

Были проведены эксперименты, выявившие зависимость области синхронизации от мощности излучения. Для этого использовались светодиодные лампы, чтобы избежать нагрева раствора реакции. При световом потоке менее $250 \mathrm{~lm}$ синхронизации колебаний не наблюдалось, происходил лишь сдвиг частоты в сторону синхронизированного сигнала. Результаты измерений приведены на рис. 2.

Из рис. 2 следует, что минимальный световой поток от лампы накаливания, при котором происходила синхронизация в относительно большом диапазоне частот, составлял $250 \mathrm{~lm}$. Видно, что изменения частоты колебаний вне полосы синхронизации наблюдаются для частоты модуляции светового внешнего воздействия $0.029,0.033,0.039$,

$3^{*}$ Письма в ЖТФ, 2018, том 44, вып. 24 
0.125 и $0.143 \mathrm{~Hz}$ при световом потоке $250 \mathrm{~lm}$. Для той же лампы на частотах из диапазона $0.04-0.1 \mathrm{~Hz}$ возникал эффект захвата частоты синхронизирующим сигналом, т.е. имело место совпадение частоты света с частотой колебаний реакции БР. При этом собственная частота осцилляций в контрольном случае в среднем составляла $0.036 \mathrm{~Hz}$. При световом потоке от источника освещения более $5000 \mathrm{~lm}$ наблюдалось прекращение процесса синхронизации (остановка автоколебаний).

На основе данных, приведенных на рис. 2, можно сделать вывод, что при увеличении светового потока излучения диапазон синхронизации сдвинулся в низкочастотную область, при этом его ширина изменялась сравнительно слабо. Так, при световом потоке $3000 \mathrm{~lm}$ синхронизация начиналась с $0.03 \mathrm{~Hz}$ и происходила примерно до $0.07 \mathrm{~Hz}$. Следует также отметить, что включение света всегда инициировало желтый цвет фазы реакции, а при выключении цвет раствора становился синим, при этом чем больше мощность излучения, тем с большей скоростью происходили изменения цвета. При некоторых частотах периодического воздействия света цвет раствора реакции БР до включения света становился желтым либо при включении освещения резко переходил из синего в желтый. Следует отметить, что при световом потоке излучения более $1200 \mathrm{~lm}$ цвет раствора на последних осцилляциях начинал переходить в синий цвет еще до момента выключения освещения. При более низком световом потоке $(250 \mathrm{~lm})$ такого не происходило: пока есть освещение, среда реакции желтая. При воздействии светового потока от лампы более $5000 \mathrm{~lm}$ наблюдалось „выключение“ реакции, возможно из-за того, что скорости образования промежуточных веществ настолько велики, что происходил слишком высокий рост концентраций данных интермедиатов, при котором система переходила из состояния автоколебательного режима в стационарное состояние.

Таким образом, показана возможность существования в растворе с автоколебательной реакцией Бриггса-Раушера характерных для радиоэлектронных автоколебательных систем эффектов: синхронизации, изменения частоты колебаний вне полосы синхронизации и „выключения“" автоколебаний в результате периодического светового воздействия белым светом. Наблюдавшиеся закономерности могут представлять интерес при исследовании влияния световых воздействий на биообъекты, для которых, как отмечалось в [6], характерна биохимическая периодичность. Из полученных в работе результатов следует, что такого рода периодичностью можно управлять внешним световым воздействием.

Письма в ЖТФ, 2018, том 44, вып. 24 


\section{Список литературы}

[1] Briggs T.S., Rausher W.C. // J. Chem. Ed. 1973. V. 50. N 7. P. 96.

[2] Гарел Д., Гарел О. Колебательные химические реакции. М.: Мир, 1986. 146 с.

[3] Вавилин В.A. // Природа. 2005. № 6. С. 52-59.

[4] Dulos E., De Kepper P. // Biophys. Chem. 1983. V. 18. N 3. P. 211-223.

[5] Усанов Д.А., Рыткин А.П. Письма в ЖТФ. 2016. Т. 42. В. 12. С. 45-50.

[6] Шноль С.Э. // Соросовский образовательный журнал. 1996. № 7. С. 26-32.

Письма в ЖТФ, 2018, том 44, вып. 24 